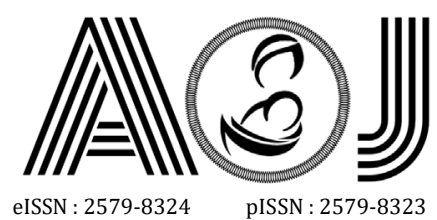

eISSN : 2579-8324
pISSN : 2579-8323

\title{
RESEARCH
}

\section{Differences of Reeda Scale in Wound Incision Abdomen Post Obstetrics / Gynaecology Laparotomy with Topical Virgin Coconut Oil (VCO) and Without Topical Virgin Coconut Oil (VCO)}

\author{
Nanda Tri Wahdini ${ }^{1}$, Ferdinal Ferry ${ }^{2}$, Sumaryati Syukur ${ }^{3}$ \\ Affiliation author: 1. Obstetrics and Gynecology, Faculty of Medicine, Andalas University, Mutiara \\ Bunda Hospital Padang; 2. Sub Division of Social Obstetrics and Gynecology, Obstetrics and \\ Gynecology Department, Faculty of Medicine, Andalas University, Dr. M. Djamil Central General \\ Hospital Padang; 3. Study Program of Chemistry, Faculty of Mathematcs and Natural Sciences, \\ Andalas University, Padang
}

Correspondence to: Nanda Tri Wahdini, email: nandatriwahdini@gmail.com, Hp: 081268539675

\begin{abstract}
Introduction : Wounds are defects of normal anatomical structures and functions. Injuries can occur because of physical, chemical, or biological trauma. Wound healing is a complex process involving many cells, cytokines, growth factors, proteases, and extracellular matrix (ECM) that work together to restore the integrity of the injured tissue. Virgin Coconut Oil is an oil saturated with medium-chain fatty acids (MCFA), one of which is lauric acid. Based on our research, VCO has wound healing properties. Research conducted in vivo on rabbits and rats experienced an increase in collagen, fibroblast proliferation, and neovascularization which influenced accelerating wound healing.
\end{abstract}

Objective : This study aims to determine the difference in the mean REEDA scale in abdominal incision wounds after obstetric / gynecology laparotomy with topical VCO and those without topical VCO.

Material and methods: This study is an experimental research design with a randomized clinical trial that was conducted on 36 people divided into 2 groups (treatment and control). Post-obstetric / gynecology laparotomy patients were subjected to topical VCO application on the incision wound and the REEDA scale was calculated at 24, 48, and 72 hours post-surgery. Statistical analysis is using the Mann-Whitney test.

Results : Age mean of the respondents in the treatment group was $32.28 \pm 10.42$ years old, while the untreated group was $30.5 \pm 6.54$ years old. The mean REEDA scale for abdominal incision wounds applied topical VCO at 24 hours was $3.17 \pm 1.04$, at 48 hours was $2.11 \pm 1.08$, and at 72 hours was $1.39 \pm 0.85$. The mean REEDA scale for abdominal incision wounds that were not treated with topical VCO at 24 hours was $3.83 \pm 0.99$, at 48 hours was $3.11 \pm 1.37$ and at 72 hours was $2.72 \pm 1.41$. The findings of the experimental analyses showed that there was no association with the use of topical VCO in surgical wounds on a 24-hour REEDA scale ( $p>0.05$ ), there was a relationship between the use of topical VCO in surgical wounds on a 48-hour and 72-hour REEDA scale $(p<0.05)$. In the care group, the mean REEDA scale decreased by $33.4 \%$ from 24 to 48 hours and $34.1 \%$ from 48 to 72 hours.

Conclusion: There is a relationship with the use of topical VCO in post-abdominal incision wounds post obstetrics/gynaecology laparotomy with REEDA scale 48 hours and 72 hours post-surgery. The 


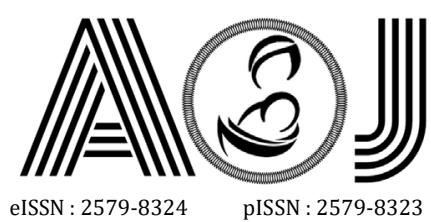

eISSN : 2579-8324
pISSN : 2579-8323

mean REEDA scale decreased by over 24 to 48 hours and 48 to 72 hours in the treatment group (who administered topical $V C O$ in postoperative incision wounds).

Keywords: VCO, REEDA scale, Wound healing

\section{BACKGROUNDS}

Human skin is the largest organ of the body protecting the outer layer, which is separated into three primary layers, the epidermis, the dermis and the subcutaneous. The skin protects the internal organs, defends against bacteria, controls body temperature, and acts as a location for touch, heat, and cold receptors. Healthy skin can shield the body from environmental influences, including physical factors such as mechanical damage, thermal injury and radiation, chemical factors such as allergens, biological factors such as microbes, viruses, and others. ${ }^{1}$

Wounds are affected by natural physiological processes and functions. ${ }^{2}$ Wounds can occur as a result of physical, chemical or biological trauma. ${ }^{3}$ Wound healing is a complex mechanism involving multiple cells, cytokines, growth factors, proteases and extracellular matrixes (ECMs) that work together to restore the integrity of the wounded tissue. While the healing process is ongoing, divide into four phases: I coagulation and haemostasis; (ii) inflammation; (iii) proliferation; and (iv) remodelling of scar tissue development. ${ }^{4}$

Wound healing remains a clinical concern, and careful and successful treatment of wounds is important. Significant investment has been made in wound care area, with a focus on innovative clinical methods and scientific advances in acute and chronic wound management. Wound healing requires a large population of cells, an extracellular matrix, and the actions of dissolved mediators such as growth factors and cytokines. The best approach to effective wound care can affect clinical outcomes. ${ }^{2}$

Coconut (Cocos nucifera) has been known for its medicinal value and therapeutic benefits and is thus referred to in Sanskrit as 'Kalpavriksha'. ${ }^{5}$ Pure coconut oil is one of the refined coconut products (Cocos nucifera). Refined coconut oil is derived from coconut milk by mechanical or natural means, with or without cooking, without chemical grinding, bleaching and coloring. ${ }^{4}$ Coconut oil is a vegetable oil composed mostly of Medium Chained Fatty Acids (MCFAs) with $92 \%$ saturated fat. The different components of coconut oil include $50 \%$ lauric acid (LA), followed by other acids such as myristic acid, caprylic acid, palmitic acid, capric acid, oleic acid, stearic acid, stearic acid and linoleic acid. Coconut oil's various benefits include antiviral, antibacterial, antifungal, antiparasitic, antithrombotic, cardioprotective, hepatoprotective, antidote, antidermatophyte, antidiabetic, insect repellent, hypolipidemic, anticholinetic, antioxidant, anticancer, anticancer, and disinfectant activity. It is also effective in fighting intestinal infections, bronchitis, asthma, and headaches. ${ }^{5}$

Virgin Coconut Oil is an oil saturated with medium-chain fatty acids (MCFAs) such as capric acid (7\%), lauric acid (49\%), myristic acid (18\%), palmitic acid (9\%), stearic acid (9\%) 


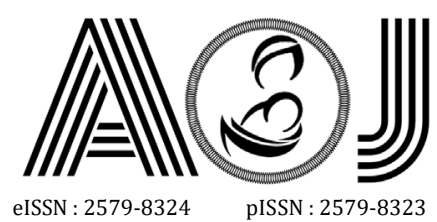

eISSN : 2579-8324
pISSN : 2579-8323

( $2 \%$ )., and small quantities of unsaturated oils such as oleic acid $(6 \%)$ and linoleic acid $(2 \%)$. $4 \mathrm{In}$ the body, lauric acid is converted to monolaurin, which is a monoglyceride agent that has antibiotic effects, including antiviral, antibacterial and antiprotozoal, so it can improve the human body resistance to the disease and accelerate the process of wound healing. ${ }^{6}$ Monolaurin, a monoester formed by a medium chain of lauric acid (fatty acid), has deep antiviral and antibacterial activity. Recognition of antimicrobial activity of lauric acid monoglyceride (monolaurin) has been documented since 1966.

Based on the research that has been conducted, VCO has soothing properties for wounds. Study on rabbits and rats was performed in vivo. Treatment of wounds with virgin coconut oil can improve healing, as shown by a decrease in the time required for complete epithelization and a higher degree of different components of the skin. VCO-treated wounds experienced increased collagen, fibroblast replication, and neovascularisation. VCO can work in wound healing because it can form a chemical barrier that can shield the wound from dust, air, and viruses, so that the bacteria cannot infect the wound. Wounds that are not infected are easier to cure. Expression of COX-2 involving VCO as a sample that will influence the neovascularisation, migration and distribution of fibroblasts. ${ }^{4}$

One of the commonly used criteria for wound healing is the REEDA scale. The REEDA scale (Redness, edema, Ecchymosis, Discharge, Approximation) is a wound healing assessment method that includes five parameters, including redness, edema, ecchymosis, discharge and approach (approximation) of two wound edges. Each aspect is assigned a score between 0 and 3, which shows signs for the presence of the highest-level signs. Thus, the overall score varies from 0 to 15 , with higher scores reflecting poor wound healing. ${ }^{7}$

Based on the background described above, researchers are interested in conducting research on differences in the REEDA scale of obstetric/gynaecological laparotomy postabdominal incision wounds due to topical Virgin Coconut Oil (VCO) and without topical Virgin Coconut Oil (VCO).

\section{METHODS}

This method of study is an experimental design of a randomized clinical trial of 36 individuals separated into 2 categories. Patients post-obstetric/gynaecology laparotomy, VCO topically applied to the incision wound, and REEDA scale measurement at 24, 48, and, 72 hours postoperative. Statistical analysis is using the Mann-Whitney test.

Before this research began, an ethical clearance was submitted to the Research Ethics Commission Team of the Faculty of Medicine, Andalas University, and had received an ethical clearance statement number 291 / KEP / FK / 2020. 


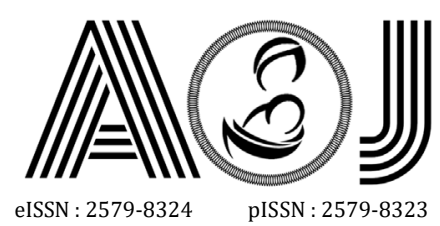

Editorial Room Andalas Obstetrics and Gynecology Journal, $3^{\text {rd }}$ floor of KSM of Obstetrics and Gynecology,

RSUP DR. M. Djamil Padang, Jl. Perintis Kemerdekaan Padang, Sumatera Barat 25127

Website:

http://jurnalobgin.fk.unand.ac.id/index.php/JOE

\section{RESULTS}

\section{Characteristics of Research Respondents}

The characteristics of the research respondents can be seen in Table 1 below:

Table 1. Research Respondents Characteristics

\begin{tabular}{lcc}
\hline \multicolumn{1}{c}{ Characteristics } & $\begin{array}{c}\text { Treatment Group } \\
\text { Mean } \pm \text { SD }\end{array}$ & $\begin{array}{c}\text { Untreated Group } \\
\text { Mean } \pm \text { SD }\end{array}$ \\
\hline Age (years) & $32.28 \pm 10.42$ & $30.5 \pm 6.54$ \\
$\mathrm{Hb}(\mathrm{gr} / \mathrm{dL})$ & $11.73 \pm 1.14$ & $11 \pm 1.37$ \\
$\mathrm{GDS}(\mathrm{gr} / \mathrm{dl})$ & $102.06 \pm 29.51$ & $82.94 \pm 14.38$ \\
Albumin & $3.82 \pm 0.59$ & $3.99 \pm 0.50$ \\
$\mathrm{BMI}$ & $25.04 \pm 3.70$ & $26.52 \pm 2.16$ \\
Operation duration (minutes) & $96.94 \pm 39.30$ & $54.17 \pm 12.04$ \\
Parity & & \\
$-\quad \quad$ Primipara & $2(33.3)$ & $4(66,7)$ \\
$-\quad$ Multiparous & $9(39.1)$ & $14(60.9)$ \\
$-\quad$ Gynecological Cases & $7(100)$ & $0(0)$ \\
\hline
\end{tabular}

Table 1 shows the mean age of the respondents in the treatment group was $32.28 \pm$ 10.42 years old, while in the untreated group was $30.5 \pm 6.54$ years old. The average $\mathrm{Hb}$ level in the treatment group was $11.73 \pm 1.14 \mathrm{~g} / \mathrm{dL}$, while in the untreated group $11 \pm 1.37 \mathrm{~g} / \mathrm{dL}$. The mean GDS and albumin levels in the treatment group were $102.06 \pm 29.51 \mathrm{gr} / \mathrm{dl}$ and 3.82 \pm 0.59 , while those in the untreated group were $82.94 \pm 14.38 \mathrm{gr} / \mathrm{dl}$ and $3.99 \pm 0.50$. Half of the treatment group, specifically $9(39.1 \%)$ respondents were multiparous and $14(60.9 \%)$ respondents in the untreated group were multiparous. The mean BMI in the treatment group was $25.04 \pm 3.70$ while in the untreated group was $26.52 \pm 2.16$. The mean duration of operation in the treatment group was $96.94 \pm 39.30$ minutes, while in the untreated group was $54.17 \pm 12.04$ minutes.

\section{Normality test}

The normality test is using the Shapiro-Wilk test to determine whether the data is normally distributed or not. The results of the data normality test shown in Table 2 below:

Table 2 Data Normality Test

\begin{tabular}{cccc}
\hline \multirow{2}{*}{ REEDA scale } & With topical VCO & Without topical VCO & \multirow{2}{*}{ p-value } \\
\cline { 2 - 3 } & Mean \pm SD & Mean \pm SD & \\
\hline 24 hours & $3.17 \pm 1.04$ & $3.83 \pm 0.99$ & 0.002 \\
48 hours & $2.11 \pm 1.08$ & $3.11 \pm 1.37$ & 0.002 \\
72 hours & $1.39 \pm 0.85$ & $2.72 \pm 1.41$ & 0.0001 \\
\hline
\end{tabular}




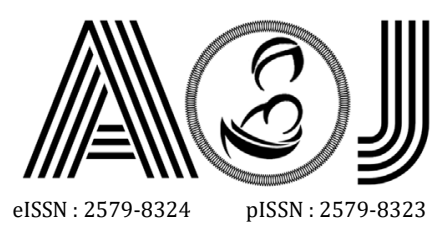

Editorial Room Andalas Obstetrics and Gynecology Journal, $3^{\text {rd }}$ floor of KSM of Obstetrics and Gynecology, RSUP DR. M. Djamil Padang, Jl. Perintis Kemerdekaan Padang, Sumatera Barat 25127

It is showing the REEDA scale variables at 24 hours, 48 hours, and 72 hours are not normally distributed so it requires data transformation. After the transformation was carried out, the following results were obtained:

Table 3 Data Normality Test After Data Transformation

\begin{tabular}{cccc}
\hline \multirow{2}{*}{ REEDA scale } & With topical VCO & Without topical VCO & \multirow{2}{*}{ p-value } \\
\cline { 2 - 3 } & Mean \pm SD & Mean \pm SD & \\
\hline 24 hours & $3.17 \pm 1.04$ & $3.83 \pm 0.99$ & 0.0001 \\
48 hours & $2.11 \pm 1.08$ & $3.11 \pm 1.37$ & 0.001 \\
72 hours & $1.39 \pm 0.85$ & $2.72 \pm 1.41$ & 0.0001 \\
\hline
\end{tabular}

After the transformation of the data, the distribution of the REEDA scale at 24 hours, 48 hours, and 72 hours was found to be abnormal. Therefore, non-parametric statistical tests are used.

\section{Mean REEDA Scale in Abdominal Incision Wounds With topical VCO}

The REEDA scale of the abdominal incision wound with topical VCO can be seen in Table 4 below:

Table 4 REEDA Scale on Abdomen Incision Wounds with topical VCO

\begin{tabular}{cccc}
\hline \multirow{2}{*}{ Characteristics } & 24 hours & 48 hours & 72 Hours \\
\cline { 2 - 4 } & Mean \pm SD & Mean \pm SD & Mean \pm SD \\
\hline REEDA scale & $3.17 \pm 1.04$ & $2.11 \pm 1.08$ & $1.39 \pm 0.85$ \\
\hline
\end{tabular}

Based on Table 4, it is known that the mean REEDA scale on abdominal incision wounds with topical VCO at 24 hours is $3.17 \pm 1.04$, at 48 hours is $2.11 \pm 1.08$, and at 72 hours is 1.39 \pm 0.85 .

\section{Mean REEDA Scale in Abdomen Incision Wounds without Topical VCO}

The REEDA scale for abdominal incisions without topical VCO in Table 5 below:

Table 5 REEDA Scale in Abdomen Incision Wounds without topical VCO

\begin{tabular}{cccc}
\hline \multirow{2}{*}{ Characteristics } & 24 hours & 48 hours & 72 Hours \\
\cline { 2 - 4 } & Mean \pm SD & Mean \pm SD & Mean \pm SD \\
\hline REEDA scale & $3.83 \pm 0.99$ & $3.11 \pm 1.37$ & $2.72 \pm 1.41$ \\
\hline
\end{tabular}

Based on Table 5, the mean REEDA scale in abdominal incision wounds that without topical VCO at 24 hours was $3.83 \pm 0.99$, at 48 hours was $3.11 \pm 1.37$, and at 72 hours was $2.72 \pm 1.41$. 


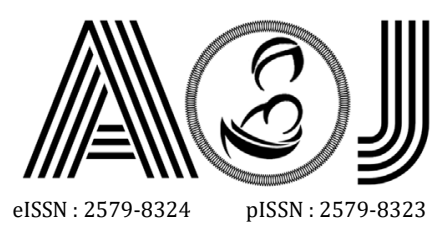
ANDALAS OBSTETRICS AND GYNECOLOGY JOURNAL Address for Correspondence:

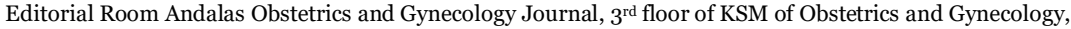
RSUP DR. M. Djamil Padang, Jl. Perintis Kemerdekaan Padang, Sumatera Barat 25127

Website:

http://jurnalobgin.fk.unand.ac.id/index.php/JOE

\section{Relationship of Using Topical VCO in Surgical Wounds with the REEDA Scale}

The relationship between using topical VCO in surgical wounds with the REEDA scale shows in Table 6 below:

Table 6 Relationship between Using Topical VCO in Surgical Wounds and the REEDA Scale

\begin{tabular}{cccc}
\hline \multirow{2}{*}{ REEDA scale } & Topical VCO was given & Without Topical VCO & \multirow{2}{*}{ p-value } \\
\cline { 2 - 3 } & Mean \pm SD & Mean \pm SD & \\
\hline 24 hours & $3.17 \pm 1.04$ & $3.83 \pm 0.99$ & 0.085 \\
48 hours & $2.11 \pm 1.08$ & $3.11 \pm 1.37$ & 0.029 \\
72 hours & $1.39 \pm 0.85$ & $2.72 \pm 1.41$ & 0.004 \\
\hline
\end{tabular}

Table 6. shows the mean REEDA scale at 24 hours for patients with topical VCO was 3.17 \pm 1.04 , while in the group without topical VCO was $3.83 \pm 0.99$. The results of statistical tests showed that there was no relationship between the use of topical VCO in surgical wounds and the 24-hour REEDA scale ( $p>0.05$ ). The mean REEDA scale at 48 hours for patients with topical VCO was $2.11 \pm 1.08$, while in the group without topical VCO was $3.11 \pm 1.37$. The results of statistical tests showed that there was a relationship between the use of topical VCO in surgical wounds and the 48-hour REEDA scale $(p<0.05)$. The mean REEDA scale at 72 hours for patients with topical VCO was $1.39 \pm 0.85$ while in the group without topical VCO it was $2.72 \pm 1.41$.

\section{Decrease in the Mean of REEDA Scale in Abdominal Incision Wounds With topical VCO and Those Without topical Vco}

Based on Table 6, it can be seen that the mean REEDA scale decreased in abdominal incision wounds with topical VCO and those without topical VCO. In the treatment group, the mean REEDA scale decreased by $33.4 \%$ from 24 to 48 hours and $34.1 \%$ from 48 to 72 hours. In the control group, the mean REEDA scale decreased by $18.8 \%$ from 24 to 48 hours and $12.3 \%$ from 48 to 72 hours.

\section{DISCUSSION}

\section{Mean REEDA Scale in Abdominal Incision Wounds With topical VCO}

Based on the results of the study, it is known that the mean REEDA scale on abdominal incision wounds with topical VCO at 24 hours is $3.17 \pm 1.04$, at 48 hours is $2.11 \pm 1.08$, and at 72 hours is $1.39 \pm 0.85$. 


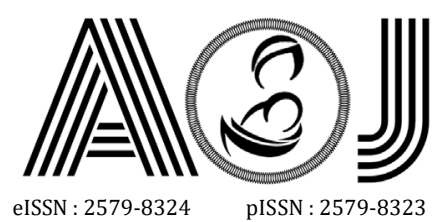

eISSN : 2579-8324
pISSN : 2579-8323

Editorial Room Andalas Obstetrics and Gynecology Journal, $3^{\text {rd }}$ floor of KSM of Obstetrics and Gynecology, RSUP DR. M. Djamil Padang, Jl. Perintis Kemerdekaan Padang, Sumatera Barat 25127

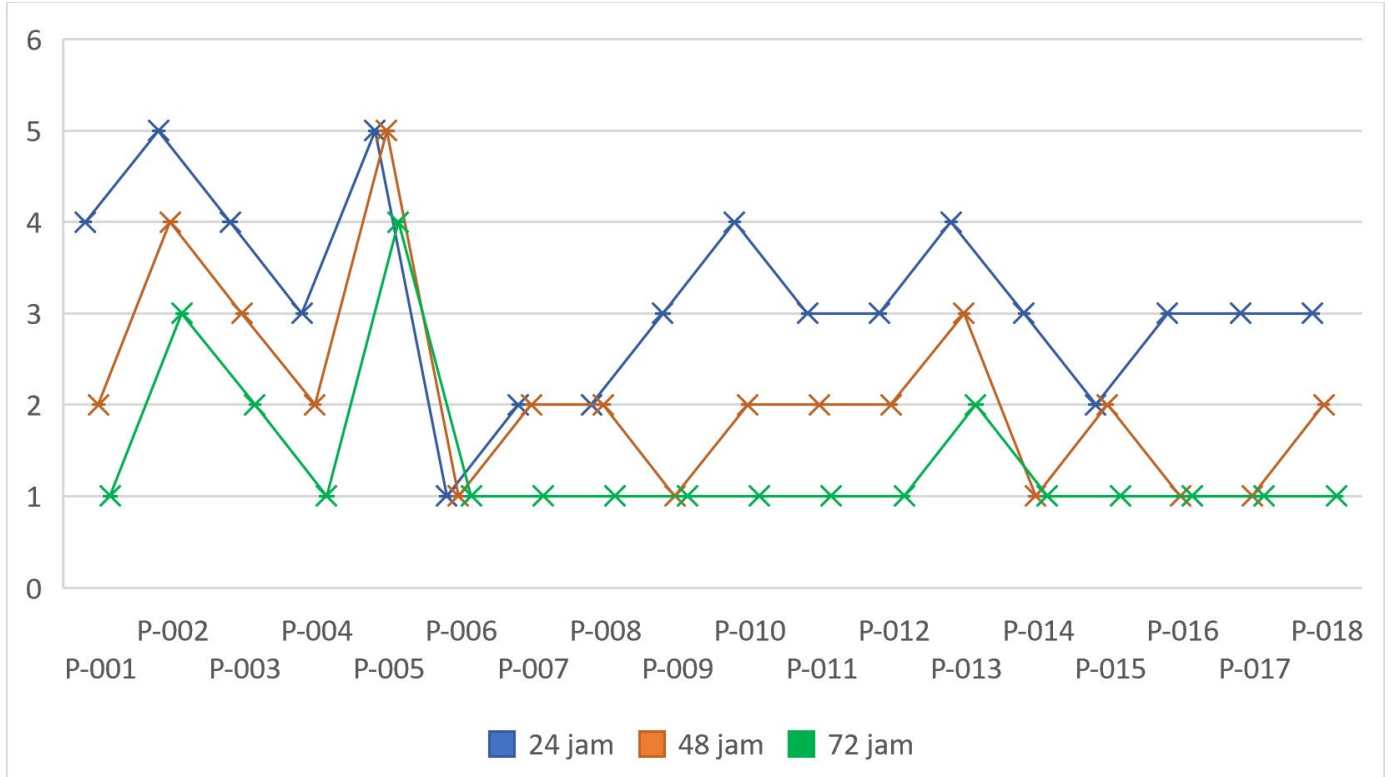

Graph 1. REEDA Scale on Abdomen Incision Wound With topical VCO

Based on graph 1 it can be seen that in the treatment group, at 24 hours, the highest REEDA scale was 5 and the lowest was 1 , with a mean of $3.17 \pm 1.04$. At 48 hours, the highest REEDA scale was 5 and the lowest was 1 , with a mean of $2.11 \pm 1.08$. At 72 hours, the highest REEDA scale was 4 and the lowest was 1 , with a mean of $1.39 \pm 0.85$. These results shows that there is a decrease in the REEDA scale in the treatment group from a mean of 24 hours, 48 hours, and 72 hours.

The REEDA scale is a wound healing assessment instrument that contains five factors, namely redness, edema, ecchymosis, discharge, and the approach (approximation) of two wound edges. ${ }^{7}$ In this study, the REEDA scale was obtained in the treatment group, at 24 hours post-surgery there were 2 people with a score scale of 5, 4 people with a score of 4, 8 people with a score of 3,3 people with a score of 2 , and 1 person with a score of 1 . At 48 Postoperative hours, obtained 1 person with a score of 5, 1 person with a score of 4, 2 people with a score of 3,9 people with a score of 2 , and 5 people with a score of 1 . At 72 hours postsurgery, 1 person got a score of 4,1 people with a score of 3, 2 people with a score of 2 , and 14 people with a score of 1 . A higher score on the REEDA scale shows poor wound healing. 7 With a decrease in the REEDA scale at 24 hours, 48 hours, and 72 hours in the wound laparotomy with VCO, showed better wound healing.

REEDA-scale study on laparotomy wounds with VCO has never been performed. However, Sumiasih (2016) conducted a study on post-partum perineal wound healing with VCO, obtained a REEDA scale in the intervention group perineal wound (with VCO smeared) 24 hours post-partum, obtained a score of $243.75 \%$, a score of $343.75 \%$, and a score of 4 $12.5 \%$. At 48 hours post-partum, a score of $0.6525 \%$ was obtained, a score of 1 was $18.75 \%$, 


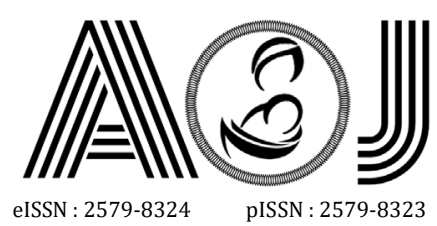

a score of 2 was 31.25\%, and a score of 3 was 43.75. At 72 hours post-partum, a score of 0 $12.5 \%$, a score of $150 \%$, and a score of $237.5 \%$. In this study, there was a decrease in the REEDA scale in perineal wounds with topical VCO at 24 hours, 48 hours, and 72 hours postpartum.21 Meanwhile, research on the REEDA scale on laparotomy wounds with VCO had never been done.

\section{Mean REEDA Scale in Abdomen Incision Wounds without Topical VCO}

Based on the results, REEDA scale in the group that was without topical VCO decreased at 24 hours, 48 hours, up to 72 hours, but the reduction was less treated group. Based on Table 5.3, the mean REEDA scale in abdominal incision wounds without topical VCO at 24 hours is 3.83 \pm 0.99 , at 48 hours is $3.11 \pm 1.37$, and at 72 hours is $2.72 \pm 1.41$.

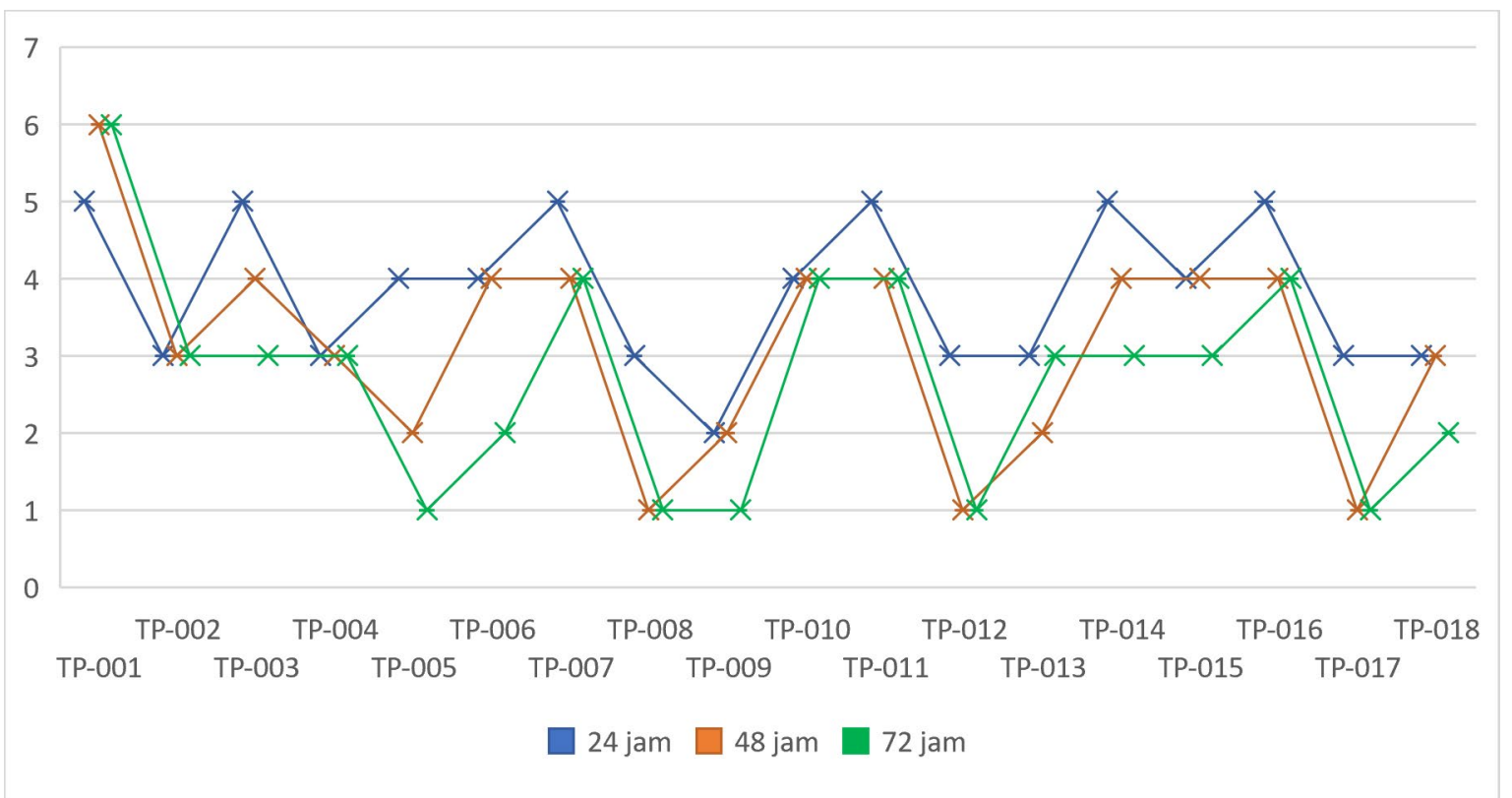

Graph 2. REEDA Scale in Abdomen Incision Wounds Without topical VCO

Graph above shows the control group, at 24 hours, the highest REEDA scale was 5 and the lowest was 2 , with a mean of $3.83 \pm 0.99$. At 48 hours, the highest REEDA scale was 6 and the lowest was 1 , with a mean of $3.11 \pm 1.37$. At 72 hours, the highest REEDA scale was 6 and the lowest was 1 , with a mean of $2.72 \pm 1.41$. From this it can be seen that there was also a decrease in the REEDA scale in the control group when viewed from a mean of 24 hours, 48 hours, and 72 hours.

In this study, the REEDA scale was obtained in the control group, at 24 hours postsurgery there were 6 people with a score scale of 5, 4 people with a score of 4,7 people with a score of 3 , and 1 person with a score of 2 . At 48 hours post-surgery, it was found 1 people with a score of 6,8 people with a score of 4,3 people with a score of 3,3 people with a score 


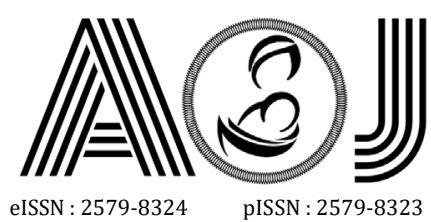

eISSN : 2579-8324
pISSN : 2579-8323

of 2 , and 3 people with a score of 1 . At 72 hours post-surgery, we got 1 person with a score of 6.4 people with a score of 4.6 people with a score of 3,2 people with a score of 2 and 5 people with a score of 1 . With a decrease in the REEDA scale at 24 hours, 48 hours, and 72 hours in laparotomy wounds without VCO, showed a better wound healing. There were 1 sample that experienced an increase and 2 samples that did not change on the REEDA scale of 24 hours, 48 hours, and 72 hours. Based on the literature, many factors influence wound healing, oxygenation, infection, age, steroid hormones, stress, diabetes, drugs, obesity, alcohol, smoking, and nutrition. ${ }^{8}$

Research conducted by Sumiasih (2016) obtained a REEDA scale on the perineal wound of the control group (without VCO applied) 24 hours post-partum, obtained a score of 2 $12.50 \%$, a score of $331.25 \%$, and a score of $456.25 \%$. At 48 hours post-partum, a score of 2 $25 \%$, a score of 3 was $68.75 \%$, and a score of 4 was $6.25 \%$. At 72 hours post-partum, a score of $287.5 \%$ and a score of 3 was $12.5 \% .21$ In this study, there was a decrease in the REEDA scale in the control group, namely perineal wounds that without topical VCO at 24 hours, 48 hours, and 72 hours post-partum.

\section{Relationship Using Topical VCO in Surgical Wounds with the REEDA Scale}

The results showed that there was a relationship between the use of topical VCO in surgical wounds with the REEDA scale at 48 hours and 72 hours. The REEDA scale in the treatment group shows a lower value than the untreated group.

In this study the mean REEDA scale at 48 hours for patients who were with topical VCO was $2.11 \pm 1.08$, while in the group without topical VCO was $3.11 \pm 1.37$. These shows that there is a relationship between the use of topical VCO in surgical wounds and the 48-hour REEDA scale $(p<0.05)$. The mean REEDA scale at 72 hours for patients with topical VCO was $1.39 \pm 0.85$ while in the group without topical VCO was $2.72 \pm 1.41$. This shows that there is a relationship between using topical VCO in surgical wounds with a 72 hours REEDA scale ( $p$ $<0.05)$. Meanwhile, there was no association $(p>0.05)$ in the surgical wound with a 24 -hour REEDA scale in patients with topical VCO, i.e. $3.17 \pm 1.04$, while in group without topical VCO $3.83 \pm 0.99$.

This study is consistent with the findings of research conducted by Sumiasih (2016) on the impact of the use of VCO on perineal wounds on the REEDA scale that the use of topical VCO can accelerate perineal wounds healing. Sumiasih reported that the REEDA scale on perineal wounds with VCO had a lower REEDA scale relative to perineal wounds that had not been coated with VCO. This shows that the wound healing process using VCO is faster. ${ }^{9}$

VCO has wound healing properties, research performed by Meliala (2019) that VCO has an in vivo impact on rabbits and rats and that wound treatment with virgin coconut oil can improve healing, as showed by the reduction in time needed for complete epithelialization. 


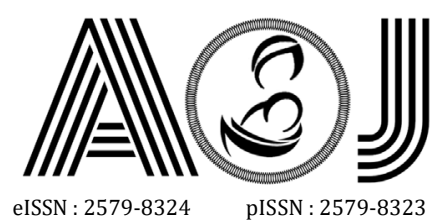

eISSN : 2579-8324
pISSN : 2579-8323

VCO-treated wounds experienced increased collagen, fibroblast proliferation, and neovascularisation. VCO can work in wound healing because it can form a chemical barrier that can shield the wound from dust, air, and viruses, so that the bacteria cannot infect the wound. Wounds that are not contaminated are easier to treat. Expression of COX-2 will enhance the involvement of VCO as a sample that will influence the neovascularisation, migration and distribution of fibroblasts. ${ }^{4}$ COX-2 plays a role in the angiogenesis development. COX-2 expression affects the mechanism of angiogenesis, migration and proliferation of fibroblasts, which are very important for wound healing. COX-2 expression influences the mechanism of angiogenesis, migration and spread of fibroblasts. ${ }^{10}$ Cyclooxygenase-2 (COX-2) is an enzyme which plays an important role in various pathophysiological processes, including inflammation, atherosclerosis, tissue injury, angiogenesis and tumorigenesis. ${ }^{10}$

Ebeling et al. (2014), COX-2 is one parameter of wound healing. Ebeling et al., Confirmed upregulation in an ex-vivo swine wound healing model for IL-6 and COX-2. They provide evidence for COX-2 and IL- 6 that the increase in mRNA is due to the stabilizing effect of mRNA, a process in which p38 MAPK and HuR (human R antigen) are essentially involved. ${ }^{10}$

Ibrahim et al (2017) showed that the effects of FVCO (Fermented Virgin Coconut Oil) on HUVEC, CCD-18, and the viability of RGC-5 cells were evaluated by the in vitro CCK8 test. Compared to the control group, the viability of HUVECs cells at levels of FVCO 6, 12, 25, and $50 \mathrm{\mu g} / \mathrm{mL}$ increased by $20 \%, 30 \%, 25 \%$, and $10 \%$. The viability of RGC- 5 cells to levels of FVCO 3,6 , and $12 \mu \mathrm{g} / \mathrm{mL}$ increased by $15 \%, 14 \%$, and $10 \%$. The viability of CCD-18 cells with FVCO levels of $3,6,12$, and $25 \mu \mathrm{g} / \mathrm{mL}$ was $13 \%, 16 \%, 14 \%$, and $12 \%$. According to result FVCO increased the proliferation of these cells. ${ }^{11}$

The study also investigated the effect of FVCO on the migration ability of RGC-5 and CCD-18 cells. After 12 hours, the percentage of wound closure of RGC- 5 cells with FVCO 3 and $6 \mu \mathrm{g} / \mathrm{mL}$ was $75 \pm 1 \%$ and $73 \pm 2.4 \%$ and showed significant differences compared to the control group of $58 \pm 1.2 \%$. After 18 hours, the percentage of wound closure at FVCO 3 and 6 $\mu \mathrm{g} / \mathrm{mL}$ was $89 \pm 2 \%$ and $87 \pm 2.7 \%$, these results also showed a significant difference compared to the control group of $75 \pm 2.5 \%$. FVCO did not affect cell morphology, where in the FVCO-treated cell group and the control group showed the same cell morphology after 24-hour incubation. ${ }^{11}$

The cell group with FVCO showed an effect where the wound size was smaller and the percentage of wound healing was higher than the control group since day 8 . The wound healing time in the treated group was 16 days, while in the control group 20 days. Our finding shows that FVCO increased the length of the blood vessels and accelerated the formation of blood vessels in mice. ${ }^{11}$ 


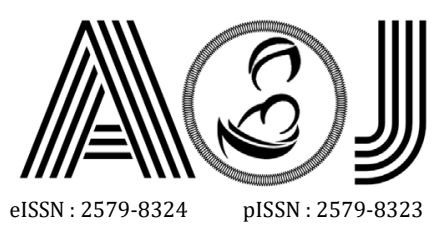

\section{Decreased Average REEDA Scale in Abdominal Incision Wounds With topical VCO and without Topical VCO}

The results showed a decrease in the mean REEDA scale in abdominal incision wounds with topical VCO and those without topical VCO. In the treatment group, the mean REEDA scale decreased by $33.4 \%$ from 24 to 48 hours and $34.1 \%$ from 48 to 72 hours. In the control group, the mean REEDA scale decreased by $18.8 \%$ from 24 to 48 hours and $12.3 \%$ from 48 to 72 hours. From these results it can be seen that there is a decrease in the mean REEDA scale greater than 24 to 48 hours and 48 to 72 hours in the treatment group (who received topical VCO in postoperative incision wounds).

This is in line with by Meliala (2019) finding regarding VCO and wound healing, that VCO has an in vivo effect on rabbits and rats and that wound treatment with virgin coconut oil can speed up healing, as shown by the reduction in time it takes to complete epithelialization. ${ }^{10}$

\section{CONCLUSSION}

This research showed that there was a relationship with the use of topical VCO in postoperative abdominal incision wounds. Obstetrics/Gynaecology Laparotomy with REEDA scale 48 hours and 72 hours post-surgery. The mean REEDA scale decreased by over 24 to 48 hours and 48 to 72 hours in the treatment group (who administered topical VCO in postoperative incision wounds).

\section{REFERENCES}

1. Ariffin NHM, Hasham R. Potential Dermatological Application on Asian Plants. Biotechnol Bioprocess Eng. 2016; 21: 337-354.

2. Velnar T, Bailey T, Smrkolf V. The Wound Healing Process: an Overview of the Cellular and Molecular Mechanisms. The Journal of International Medical Research. 2009; 37: 1528-1542.

3. Giri JV. Factors Affecting Wound Healing. 20th Annual Conference of Indian Society of Wound Management; 2018.

4. Trophies, Perbina DI. The Effect of Pure Coconut Oil and Its Hydrolysis Results on Wound Parameters in 3T3 NIH Cells by In Vitro. Medan: Faculty of Pharmacy, University of North Sumatra; 2019.

5. Salian V, Shetty P. Coconut Oil and Virgin Coconut Oil: An Insight into its Oral and Overall Health Benefits. Journal of Clinical and Diagnostic Research. 2018; 12: 1-3.

6. Widiyanti RA. Utilization of Coconut as VCO (Virgin Coconut Oil) as Health Antibiotics in Supporting the Vision of a Healthy Indonesia 2015. National Seminar on Biology Education 2015; March 21 2015, 2015; Poor. 


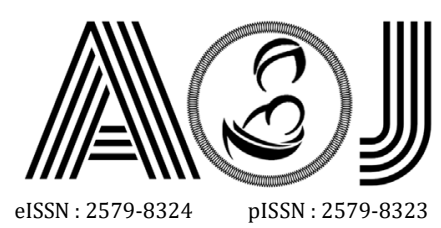

elSSN : 2579-832

Editorial Room Andalas Obstetrics and Gynecology Journal, $3^{\text {rd }}$ floor of KSM of Obstetrics and Gynecology,

7. Molazem Z, Mohseni F, Younesi M, Keshhavarzi S. Aloe vera gel and cesarean wound healing; A randomized controlled clinical trial. Global Journal of Health Science. 2015; 7: 203-209.

8. Guo S, DiPietro LA. Factors Affecting Wound Healing. J Dent Res. 2010; 89: 219-229.

9. Sumiasih N, Somoyani N, Armini N. Virgin coconut oil accelerates the healing of perineal wounds at inpatient health centers in Denpasar. Husada Scale Journal. 2016; 13: 39-49.

10. Silalahi J, Yuandani Y, Meliala D, Margata L, Satria D. The activity of Hydrolyzed Virgin Coconut Oil to increase proliferation and Cyclooxygenase-2 expression towards on NIH 3T3 cell line in wound healing process. Open Access Macedonian Journal of Medical Sciences. 2019;7:3164-3168.

11. Ibrahim AH, Li H, Al-Rawi SS, Majid ASA, Al-Habib OA, Xia X. Angiogenic and Wound Healing Potency of Fermented Virgin Coconut Oil : in Vitro and in Vivo Studies. Am J Transl Res. 2017;9:4936-4944. 